\title{
Vitamin D receptor Bsml polymorphism and osteoporosis risk in post-menopausal women
}

\author{
Bizeng Zhao, Wei Zhang, Shengchao Du, Zubin Zhou
}

Department of Orthopedics, Shanghai $6^{\text {th }}$ People's Hospital of Shanghai Jiaotong University, Shanghai, China

Submitted: 28 September 2013

Accepted: 11 December 2013

Arch Med Sci 2016; 12, 1: 25-30

DOI: 10.5114/aoms.2016.57475

Copyright $\odot 2016$ Termedia \& Banach

\section{Abstract}

Introduction: Many studies have suggested that the vitamin D receptor polymorphism Bsml might be associated with the risk of osteoporosis development in post-menopausal women. However, the results have been inconsistent. The aim of this meta-analysis was to derive a more precise evaluation of the relationship.

Material and methods: Published literature from PubMed, EMBASE and the CNKI database was searched. Crude odds ratios (ORs) with 95\% confidence intervals (Cls) were used to assess the strength of any association.

Results: Ten case-control studies were included with a total of 1,403 osteoporosis cases and 2,144 healthy controls. In the overall analysis, no significant association was found between Bsml polymorphism and osteoporosis risk (BB vs. bb: $\mathrm{OR}=0.76,95 \% \mathrm{Cl}=0.39-1.48$; $\mathrm{BB}$ vs. $\mathrm{Bb}$ : $\mathrm{OR}=0.90$, $95 \% \mathrm{Cl}=0.71-1.15$; dominant model: $\mathrm{OR}=1.20,95 \% \mathrm{Cl}=0.74-1.93$; recessive model: $\mathrm{OR}=0.83,95 \% \mathrm{Cl}=0.53-1.30)$. In the subgroup analysis by ethnicity, the results showed similar result that Bsml polymorphism $\mathrm{m}$ had no association with osteoporosis.

Conclusions: Results from the current meta-analysis suggest that vitamin $D$ receptor Bsml polymorphism may not be a risk factor for osteoporosis in post-menopausal women.

Key words: vitamin D receptor, Bsml polymorphism, osteoporosis, metaanalysis.

\section{Introduction}

Osteoporosis is a common complex genetic disease in postmenopausal women, characterized by decreased bone mineral density (BMD), increased bone fragility and fracture risk. It is a major public health issue [1]. The World Health Organization estimates that 200 million women and men suffer from osteoporosis worldwide [2]. In the United States and the European Union, approximately 30\% of all postmenopausal women have osteoporosis, and it has been predicted that more than $40 \%$ of them will suffer one or more fragility fractures during their remaining lifetime [3]. Many environmental factors have been identified as risk factors of osteoporosis, including exercise and calcium intake [4]. In addition, twin and family studies have shown that approximately $50-85 \%$ of heritability for BMD in the general population may be attributed to genetic factors [5]. Genetic factors may also play a role in the development of osteoporosis [6].

\author{
Corresponding author: \\ Zubin Zhou \\ Department of Orthopedics \\ Shanghai $6^{\text {th }}$ People's \\ Hospital \\ of Shanghai Jiaotong \\ University \\ Shanghai 200233, China \\ E-mail: \\ zhouzubin@yahoo.com
}


Vitamin D plays a crucial role in calcium and phosphate homeostasis and skeletal metabolism. Furthermore, the vitamin D receptor (VDR) plays an important role in cellular differentiation and the control of proliferation in a variety of cell types. The VDR gene located on the long arm of chromosome 12 (12q13.11) is a member of the nuclear receptor superfamily, and many studies have shown that VDR gene polymorphisms play an important role in the pathogenesis of osteoporosis [7]. VDR polymorphisms include VDR Taql (rs17880019), VDR Bsml (rs1544410), VDR Fokl (rs17881966), and VDR Apal (rs17879735) $[8,9]$.

Bsml gene polymorphism is an important subtype of VDR gene polymorphisms, with genotypes $\mathrm{BB}, \mathrm{Bb}$, or bb by polymerase chain reactions based on polymorphism at the Bsml restriction site. Since 1996 when Berg et al. first reported that VDR Bsml polymorphism could affect osteoporosis in postmenopausal women [10], to date, a great number of studies regarding the association between Bsml gene polymorphism and osteoporosis in postmenopausal women have been published. However, the results remain controversial. The aim of this study was to investigate the association between Bsml gene polymorphism and osteoporosis risk in postmenopausal women by conducting a meta-analysis from all eligible case-control studies published.

\section{Material and methods}

\section{Search strategy}

The study retrieval was conducted using PubMed, EMBASE and the China National Knowledge Infrastructure (CNKI) databases with the following keywords: "Bsml polymorphism", "vitamin D receptor", and "osteoporosis" dating up until July of 2013. The references of the eligible articles or textbooks were also reviewed to check through manual searches to find other potential studies. When pertinent data were not included, or data that were presented were unclear, the authors were contacted directly. Any disagreement was resolved by discussion between the authors.

\section{Selection criteria}

The resulting reports were filtered using the following inclusion criteria: (i) case-control studies that addressed osteoporosis cases and healthy controls; (ii) studies on the association of VDR Bsml polymorphism and susceptibility to osteoporosis; (iii) studies that included sufficient genotype data for extraction. The following studies were excluded: (i) not case-control studies that evaluated the association between VDR Bsml polymorphism and osteoporosis risk; (ii) case reports, letters, reviews, and editorial articles; (iii) reports in which the number of null and wild genotypes could not be ascertained.

\section{Data extraction}

Two investigators (Bizeng Zhao and Wei Zhang) independently extracted the data with a standard protocol and the results were reviewed by a third investigator (Zubin Zhou). Discrepancies were resolved by discussion with our research team. For each study, the following characteristics were collected: the first author, year of publication, country of the study and ethnicity, genotype method, allele and genotype frequencies, and evidence of Hardy-Weinberg equilibrium (HWE) in controls. Different ethnic descents were categorized as European and Asian that included subjects of more than one ethnicity.

\section{Statistical analysis}

We calculated the odds ratio (OR) and corresponding 95\% confidence interval $(\mathrm{Cl})$ to evaluate the association between the VDR Bsml polymorphism and osteoporosis risk under a homozygote comparison (BB vs. bb), a heterozygote comparison (BB vs. Bb), a dominant model ( $b b$ $+\mathrm{Bb}$ vs. $\mathrm{BB})$ and a recessive mode $(\mathrm{BB}+\mathrm{Bb}$ vs. bb) between groups. We quantified the effect of heterogeneity by using the ${ }^{2}$ test, which ranges from 0 to $100 \%$ and represents the proportion of inter-study variability that can be contributed to heterogeneity rather than chance $[11,12]$. When $I^{2}>50 \%$ indicated heterogeneity across studies, the random effects model was used for meta-analysis, or else the fixed effects model was used. Subgroup analysis was performed according to ethnicity. The different ethnicities were categorized as Asians and Europeans. To test for robustness of the summary effects, sensitivity analysis was performed by comparison of random effect model values to the fixed effect to ensure the stability of the findings. All analyses were conducted using Stata 12.0 (Stata-Corp LP, College Station, TX, USA).

\section{Results}

\section{Studies and data included}

According to the inclusion criteria, 10 studies were included [10,13-20]. The flow chart of the study selection is shown in Figure 1 . The total osteoporosis cases and healthy controls numbered 1403 and 2144 respectively, in the 10 case-control studies that evaluated the relationship between Bsml polymorphism and the risk of osteoporosis. The publication year of the involved studies ranged from 1996 to 2009. Of the 10 included studies, 9 used the restriction fragment length polymorphism (PCR-RFLP) method and one used the TKM method [18]. Meta-analysis of the relationship between VDR gene Bsml polymorphism and oste- 


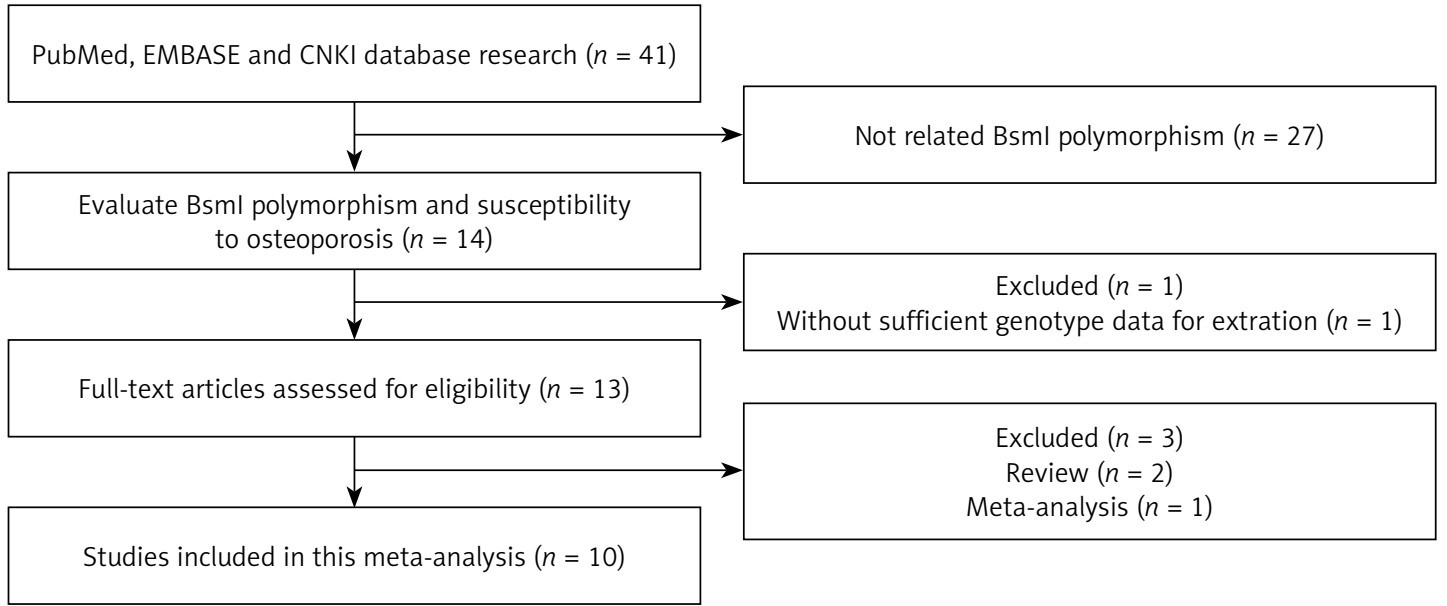

Figure 1. Flow chart showing study selection procedure

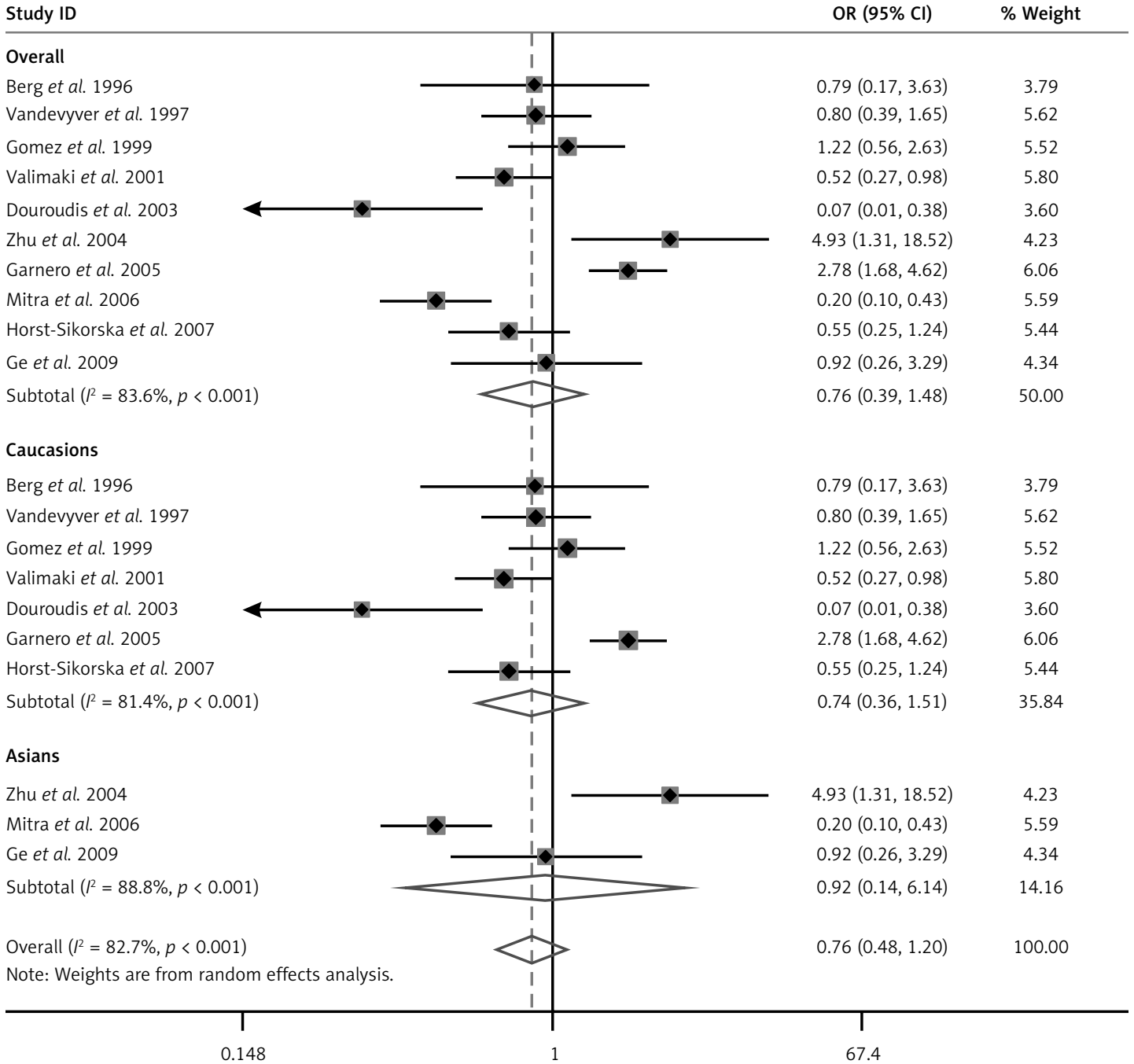

Figure 2. Meta-analysis of the relationship between VDR gene Bsml polymorphism and osteoporosis risk using BB vs. bb model

oporosis risk using BB vs. bb model (Figure 2). The HWE test was performed on the genotype distribution of the controls in all included studies. All of them were in HWE except those of Douroudis et al., Zhu et al. and Ge et al. The main characteristics of included studies are listed in Table I. Of these studies, 7 reported on Europeans, and 3 reported on Asians. 
Table I. Characteristics of studies included in the meta-analysis

\begin{tabular}{|c|c|c|c|c|c|c|c|c|c|c|c|}
\hline \multirow[t]{2}{*}{ First author } & \multirow[t]{2}{*}{ Year } & \multirow[t]{2}{*}{ Country } & \multirow[t]{2}{*}{ Ethnicity } & \multirow[t]{2}{*}{$\begin{array}{l}\text { Genotyping } \\
\text { method }\end{array}$} & \multicolumn{3}{|c|}{$\begin{array}{l}\text { Genotypes } \\
\text { for cases }\end{array}$} & \multicolumn{3}{|c|}{$\begin{array}{l}\text { Genotypes } \\
\text { for controls }\end{array}$} & \multirow[t]{2}{*}{$\begin{array}{l}\text { HWE } \\
\text { test }\end{array}$} \\
\hline & & & & & BB & $\mathrm{Bb}$ & $\mathrm{bb}$ & BB & $\mathrm{Bb}$ & $\mathrm{bb}$ & \\
\hline Berg & 1996 & Norway & European & RFLP & 4 & 8 & 7 & 8 & 11 & 11 & 0.16 \\
\hline Vandevyver & 1997 & Belgium & European & RFLP & 12 & 50 & 24 & 127 & 368 & 203 & 0.08 \\
\hline Gomez & 1999 & Spain & European & RFLP & 13 & 38 & 25 & 38 & 109 & 89 & 0.63 \\
\hline Valimaki & 2001 & Finland & European & RFLP & 44 & 175 & 153 & 20 & 55 & 36 & 0.90 \\
\hline Douroudis & 2003 & Greece & European & RFLP & 3 & 12 & 20 & 10 & 29 & 5 & 0.03 \\
\hline Garnero & 2005 & France & European & RFLP & 50 & 124 & 66 & 40 & 162 & 147 & 0.64 \\
\hline Horst-Sikorska & 2007 & Poland & European & RFLP & 10 & 35 & 40 & 33 & 85 & 73 & 0.34 \\
\hline Zhu & 2004 & China & Asian & RFLP & 6 & 26 & 8 & 7 & 105 & 46 & 0.00 \\
\hline Mitra & 2006 & India & Asian & TKM method & 19 & 38 & 40 & 51 & 46 & 22 & 0.05 \\
\hline Ge & 2009 & China & Asian & RFLP & 6 & 33 & 314 & 4 & 12 & 192 & 0.00 \\
\hline
\end{tabular}

RFLP - Restriction fragment length polymorphism.

Table II. Summary ORs and $95 \% \mathrm{Cl}$ of $\mathrm{Bsml}$ gene polymorphism with bone mineral density risk

\begin{tabular}{|c|c|c|c|c|c|c|c|c|c|c|}
\hline \multirow[t]{2}{*}{$\begin{array}{l}\text { Sub- } \\
\text { group }\end{array}$} & \multirow[t]{2}{*}{ Genetic model } & \multicolumn{2}{|c|}{ Sample size } & \multirow[t]{2}{*}{$\begin{array}{l}\text { Type of } \\
\text { model }\end{array}$} & \multicolumn{2}{|c|}{$\begin{array}{c}\text { Test of } \\
\text { heterogeneity }\end{array}$} & \multicolumn{2}{|c|}{$\begin{array}{c}\text { Test of } \\
\text { association }\end{array}$} & \multicolumn{2}{|c|}{$\begin{array}{l}\text { Sensitivity } \\
\text { analysis }\end{array}$} \\
\hline & & Case & Control & & $I^{2}(\%)$ & $\begin{array}{l}\text { Value } \\
\text { of } p\end{array}$ & OR & $95 \% \mathrm{Cl}$ & OR & $95 \% \mathrm{Cl}$ \\
\hline \multirow[t]{4}{*}{ Overall } & BB vs. bb & 1403 & 2144 & Random & 83.6 & $<0.001$ & 0.76 & $0.39-1.48$ & 0.87 & $0.68-1.11$ \\
\hline & BB vs. Bb & & & Fixed & 42.8 & 0.06 & 0.90 & $0.71-1.15$ & 0.88 & $0.61-1.26$ \\
\hline & Dominant model & & & Random & 71 & $<0.001$ & 1.20 & $0.74-1.93$ & 1.15 & $0.92-1.43$ \\
\hline & Recessive model & & & Random & 81.4 & $<0.001$ & 0.83 & $0.53-1.30$ & 0.97 & $0.82-1.15$ \\
\hline \multirow[t]{4}{*}{ European } & BB vs. bb & 978 & 1692 & Random & 78.3 & $<0.001$ & 0.74 & $0.36-1.51$ & 1.01 & $0.76-1.32$ \\
\hline & BB vs. Bb & & & Fixed & 8.3 & 0.37 & 0.96 & $0.74-1.26$ & 0.93 & $0.68-1.28$ \\
\hline & Dominant model & & & Random & 59.8 & 0.02 & 1.14 & $0.75-1.74$ & 1.01 & $0.80-1.29$ \\
\hline & Recessive model & & & Random & 81.5 & $<0.001$ & 0.77 & $0.48-1.26$ & 0.98 & $0.81-1.18$ \\
\hline \multirow[t]{4}{*}{ Asian } & BB vs. bb & 490 & 485 & Random & 88.8 & $<0.001$ & 0.92 & $0.14-6.14$ & 0.51 & $0.30-1.07$ \\
\hline & BB vs. Bb & & & Random & 77.5 & 0.01 & 0.92 & $0.25-3.38$ & 0.70 & $0.41-1.19$ \\
\hline & Dominant model & & & Random & 85.8 & $<0.001$ & 1.03 & $0.22-4.73$ & 1.73 & $1.07-2.82$ \\
\hline & Recessive model & & & Random & 86.8 & $<0.001$ & 0.91 & $0.31-2.68$ & 0.85 & $0.60-1.21$ \\
\hline
\end{tabular}

\section{Results of meta-analysis}

A summary of the meta-analysis findings of the association between VDR Bsml polymorphism and osteoporosis risk is shown in Table II. Meta-analysis results showed that there was no association between Bsml polymorphism and the risk of osteoporosis (BB vs. bb: $\mathrm{OR}=0.76,95 \% \mathrm{Cl}$ : 0.39-1.48; $\mathrm{BB}$ vs. $\mathrm{Bb}: \mathrm{OR}=0.90,95 \% \mathrm{Cl}$; 0.71-1.15; dominant model: $\mathrm{OR}=1.20,95 \% \mathrm{Cl}: 0.74-1.93$; recessive model: $\mathrm{OR}=0.83,95 \% \mathrm{Cl}: 0.53-1.30)$. In the subgroup analysis based on ethnicity, the included studies were divided into Asian and European populations, and the results also showed no significant association between Bsml polymorphism and susceptibility to osteoporosis in both Asian and European populations. Sensitivity analysis was performed by comparing random effect model values to the fixed effect, and the significance of pooled OR in all individual analyses and subgroup analyses was not influenced.

\section{Publication bias}

The publication bias of the meta-analysis of the association between VDR Bsml polymorphism and osteoporosis risk was detected by Begg's funnel plot. All graphical funnel plots of the included studies appeared to be symmetrical. There was no visual evidence of publication bias visually from the funnel plot, which implied that the publication bias was low in the present overall meta-analysis (BB 
vs. bb: $p=0.806 ; \mathrm{BB}$ vs. $\mathrm{Bb}: p=0.806$; dominant model: $p=0.806$; recessive model: $p=0.806)$.

\section{Discussion}

Osteoporosis is a multifactorial disorder with a strong genetic component, and the VDR gene has been suggested as a candidate gene for osteoporosis [21]. The VDR gene has been widely studied due to its crucial role in the regulation of bone turnover and homeostasis. Active vitamin $D$ as the ligand of VDR plays an important role in intestinal and renal calcium absorption, as well as subsequent, normal bone mineralization and remodeling [22]. VDR Bsml gene polymorphism is one of the most important subtypes of VDR gene polymorphisms. To date, a variety of studies has been conducted to identify whether the VDR Bsml polymorphism was the genetic determiner of osteoporosis. However, conflicting results have been obtained. Zintzaras et al. performed a meta-analysis to study the relationship between VDR gene polymorphism and the risk of osteoporosis, and found that there was no evidence of a relationship between Bsml polymorphism and osteoporosis risk [23]. Post-menopausal women were regarded as a 'high-risk' population for low osteoporosis; therefore, we conducted a meta-analysis to evaluate the relationship between VDR Bsml gene polymorphism and susceptibility to osteoporosis. Our meta-analysis is the first to examine this relationship of VDR Bsml gene polymorphism with osteoporosis risk in post-menopausal women. Overall, the results showed that the VDR Bsml polymorphism may not be an osteoporosis susceptibility gene in post-menopausal women. Considering that the result may be affected by ethnicity, we performed a race-related subgroup analysis, and again no significant association was found between Bsml polymorphism and susceptibility to osteoporotic fracture in post-menopausal women in both Caucasian and Asian populations. Sensitivity analysis was performed by comparing random effect model values to the fixed effect, and the result revealed that this meta-analysis was realistic and believable. There was no evidence of publication bias in this meta-analysis (all $p>0.05$ ). As the eligible study number was small in this meta-analysis, these results still need further investigation.

The potential function of Bsml polymorphism might be affected by gene-gene and gene-environment interactions. A previous study demonstrated that polymorphisms of both genes (Bsml polymorphism and estrogen receptor genotypes) increased osteoporosis risk and found that Bsml polymorphism alone did not increase the osteoporosis risk $[8,24]$. In addition, obesity can mask the effects of the VDR genotypes on BMD as reported by Dawson-Hughes $[25,26]$. As one study could not be included in our meta-analysis, further studies of gene-gene and gene-environment interactions should be taken into consideration.

The present study has some limitations. First, the number of studies included in the systematic review might have been too small to detect slight associations within ethnic groups. Second, heterogeneity exists between studies, possibly owing to covariates: age and years from onset, gender, fraction of patients among these studies, and so on.

In conclusion, our meta-analysis suggests no association between Bsml polymorphism and osteoporosis risk, both in Caucasian and Asian populations. Large-scale case-control and population-based association studies are warranted to validate the risk identified in the current meta-analysis.

\section{Conflict of interest}

All authors declared no conflict of interest.

\section{References}

1. Recker RR. Summary - novel therapies for osteoporosis. J Musculoskelet Neuronal Interact 1999; 5: 358-9.

2. Cooper C. Epidemiology of osteoporosis. Osteoporos Int 1999; 9 (Suppl. 2): S2-8.

3. Melton III LJ, Chrischilles EA, Cooper C, et al. Perspective: how many women have osteoporosis? J Bone Miner Res 1992; 7: 1005-10.

4. Nieves JW. Osteoporosis: the role of micronutrients. Am J Clin Nutr 1999; 81: 1232S-9S.

5. Riggs BL. Vitamin D-receptor genotypes and bone density. New Engl J Med 1997; 337: 125-6.

6. Recker RR. Genetic research in osteoporosis: where are we? Where should we go next? J Musculoskelet Neuronal Interact 2004; 4: 86-90.

7. Thakkinstian A, D'Este C, Eisman J, et al. Meta-analysis of molecular association studies: vitamin $D$ receptor gene polymorphisms and BMD as a case study. J Bone Miner Res 2004; 19: 419-28.

8. Deng H, Liu F, Pan Y, et al. Bsml, Taql, Apal, and Fokl polymorphisms in the vitamin $D$ receptor gene and periodontitis: a meta-analysis of 15 studies including 1338 cases and 1302 controls. J Clin Periodontol 2011; 38: 199-207.

9. Ozel L, Ata P, Ozel MS, et al. Risk factors for osteoporosis after renal transplantation and effect of vitamin D receptor Bsm I polymorphism. Transplant Proc 2011; 43: 858-62.

10. Berg JP, Falch JA, Haug E. Fracture rate, pre- and postmenopausal bone mass and early and late postmenopausal bone loss are not associated with vitamin D receptor genotype in a high-endemic area of osteoporosis. Eur J Endocrinol 1996; 135: 96-100.

11. Moher D, Liberati A, Tetzlaff J, et al. Preferred reporting items for systematic reviews and meta-analyses: the PRISMA statement. Ann Intern Med 2009; 151: 264-9.

12. Vandevyver C, Wylin T, Cassiman JJ, et al. Influence of the vitamin $D$ receptor gene alleles on bone mineral density in postmenopausal and osteoporotic women. J Bone Miner Res 1997; 12: 241-7.

13. Zintzaras E, loannidis JP. Heterogeneity testing in meta-analysis of genome searches. Genet Epidemiol 2005; 28: $123-37$ 
14. Valimaki S, Tahtela R, Kainulainen K, et al. Relation of collagen type I alpha 1 (COLIA 1 ) and vitamin D receptor genotypes to bone mass, turnover, and fractures in early postmenopausal women and to hip fractures in elderly people. Eur J Intern Med 2001; 12: 48-56.

15. Douroudis K, Tarassi K, loannidis G, et al. Association of vitamin $D$ receptor gene polymorphisms with bone mineral density in postmenopausal women of Hellenic origin. Maturitas 2003; 45: 191-7.

16. Zhu MJ, Yan XD, Wang F, et al. Relationship between vitamin $D$ receptor genotypes and bone mineral density in Guangxi Zhuang and Han nationality postmenopausal women. Chin J Osteoporos 2004; 10: 140-2.

17. Garnero P, Munoz F, Borel O, et al. Vitamin D receptor gene polymorphisms are associated with the risk of fractures in postmenopausal women, independently of bone mineral density. J Clin Endocrinol Metab 2005; 90 : 4829-35.

18. Mitra S, Desai M, Ikram Khatkhatay M. Vitamin D receptor gene polymorphisms and bone mineral density in postmenopausal Indian women. Maturitas 2006; 55: 27-35.

19. Horst-Sikorska W, Wawrzyniak A, Celczynska-Bajew L, et al. Polymorphism of VDR gene - the most effective molecular marker of osteoporotic bone fractures risk within postmenopausal women from Wielkopolska region of Poland. Endokrynol Pol 2005; 56: 233-9.

20. Ge JR, Xie LH, Chen K, et al. Association of genetic polymorphisms in several vitamin $\mathrm{D}$ receptor gene sites with bone mineral density and biochemical markers of bone turnover in postmenopausal women. J Clin Rehab Tissue Eng Res 2009; 13: 5593-6.

21. Yasovanthi J, Venkata KK, Sri MK. Association of vitamin $D$ receptor gene polymorphisms with BMD and their effect on 1, 25-dihydroxy vitamin D3 levels in pre- and postmenopausal South Indian women from Andhra Pradesh. Clin Chim Acta 2011; 412: 541-4.

22. Haussler MR, Whitfield GK, Haussler CA, et al. The nuclear vitamin D receptor: biological and molecular regulatory properties revealed. J Bone Miner Res 1998; 13: 325-49.

23. Zintzaras E, Rodopoulou P, Koukoulis GN. Bsml, Taql, Apal and Fokl polymorphisms in the vitamin $D$ receptor (VDR) gene and the risk of osteoporosis: a meta-analysis. Dis Markers 2006; 22: 317-26.

24. Gomez C, Naves ML, Barrios Y, et al. Vitamin D receptor gene polymorphisms, bone mass, bone loss and prevalence of vertebral fracture: differences in postmenopausal women and men. Osteoporos Int 1999; 10: 175-82.

25. Dawson-Hughes B, Harris SS, Finneran S. Calcium absorption on high and low calcium intakes in relation to vitamin D receptor genotypes. J Clin Endocrinol Metabol 1995; 80: 3657-61.

26. Sewerynek E, Horst-Sikorska H, Stępień-Kłos W, et al. The role of counselling and other factors in compliance of postmenopausal osteoporotic patients to alendronate 70 therapy. Arch Med Sci 2013; 9: 288-96. 